\title{
Acolhimento e orientação acadêmica no ensino remoto emergencial para os estudantes universitários
}

\author{
Welcoming and academic guidance in remote emergency learning for college students \\ Bienvenida y orientación académica en educación remota de emergencia para estudiantes \\ universitários
}

Recebido: 15/10/2021 | Revisado: 22/10/2021 | Aceito: 26/10/2021 | Publicado: 29/10/2021

\author{
Aidê Cristina Silva Teixeira \\ ORCID: https://orcid.org/0000-0002-9113-5634 \\ Universidade Federal de Minas Gerais, Brasil \\ E-mail: assessoriaeducacional@farmacia.ufmg.br \\ Thais de Souza Sales \\ ORCID: https://orcid.org/0000-0003-3081-5684 \\ Universidade Federal de Minas Gerais, Brasil \\ E-mail: thais.souzasales@hotmail.com \\ Rafael Christian de Matos \\ ORCID: https://orcid.org/0000-0003-2644-7305 \\ Universidade Federal de Minas Gerais, Brasil \\ E-mail:rafaelchristiandm@gmail.com \\ Gabriel Moreira de Mello Mendes \\ ORCID: https://orcid.org/0000-0003-1427-8401 \\ Universidade Federal de Minas Gerais, Brasil \\ E-mail:gabrielmmmendes2000@gmail.com \\ Maria do Carmo Vilas Boas Sousa \\ ORCID: https://orcid.org/0000-0001-8779-8323 \\ Universidade Federal de Minas Gerais, Brasil \\ E-mail:mariavilassboas@gmail.com \\ Cristina Duarte Vianna Soares \\ ORCID: https://orcid.org/0000-0003-3857-4264 \\ Universidade Federal de Minas Gerais, Brasil \\ E-mail:cviannas@ufmg.br
}

\begin{abstract}
Resumo
Após a suspensão das aulas e atividades presenciais, devido à pandemia de coronavírus estabelecida em 11 de março de 2020, houve necessidade de adequar, para o modo virtual e remoto, as diversas orientações temáticas, previamente fornecidas aos ingressantes. Dessa forma, após o encerramento do primeiro semestre letivo de 2020 no modo Ensino Remoto Emergencial (ERE), percebeu-se a necessidade de criação de uma disciplina, sob oferta experimental e optativa. O objetivo era abordar temáticas orientativas com a finalidade de acolher, ambientar e integrar o ingressante ao Curso de Farmácia da UFMG. Desenvolveram-se atividades virtuais e síncronas como recepção de calouros, rodas de conversa, meditação guiada, palestras, familiarização com as normas de graduação, acompanhamento didáticopedagógico de discentes, além de atividades avaliativas por meio de questionário, criações e seminários. Os depoimentos dos estudantes mostraram alta efetividade da disciplina proposta por meio de seus temas orientativos, atividades de ensino e personalizadas. Com isso, os ingressantes relataram uma transição mais amena do ensino médio para o ensino superior.
\end{abstract}

Palavras-chave: Ensino superior; Ingressante; Adaptação universitária; Acolhimento; Orientação acadêmica; Ensino remoto emergencial.

\begin{abstract}
After the suspension of in-person classes and activities, due to the coronavirus pandemic established on March 11, 2020, it was necessary to adapt, for the virtual and remote mode, various thematic guidelines, previously provided to the freshman students. Thus, after the end of the first semester of 2020 in the Remote Emergency Learning (ERE) mode, the need to create a course, under experimental and optional offer, was clear. The goal was to address the guiding themes in order to welcome, accommodate and integrate the freshmen to the UFMG -Pharmacy Course. Virtual and synchronous activities were developed, such as reception of the freshmen, conversation circles, guided meditation, lectures, acquaintance with the undergrad rules, didactic-pedagogical monitoring of students, in addition to evaluative activities by means of questionnaire, creations and seminars. The student testimonies showed a high effectiveness of
\end{abstract}


the proposed course through its guiding themes, learning and personalized activities. Thus, the freshmen reported a smoother transition from high school to higher education.

Keywords: Higher education; Freshman; University adaptation; Reception; Academic orientation; Remote emergency learning.

\section{Resumen}

Tras la suspensión de las clases y actividades presenciales, debido a la pandemia de coronavirus establecida el 11 de marzo de 2020, fue necesario adecuar, para la modalidad virtual y remota, las distintas pautas temáticas, previamente proporcionadas a los nuevos ingresantes. Después del final del primer semestre académico de 2020 en la modalidad de Enseñanza Remota de Emergencia (ERE), se percibió la necesidad de crear una disciplina, bajo una oferta experimental y opcional. El objetivo fue abordar los temas rectores con el propósito de dar la bienvenida, acoger e integrar al recién llegado al Curso de Farmacia - UFMG. Se desarrollaron actividades virtuales y sincrónicas, como recepción de estudiantes de primer año, círculos de conversación, meditación guiada, charlas, familiarización con las reglas de graduación, seguimiento didáctico-pedagógico de los estudiantes, además de actividades de evaluación a través de un cuestionario, creaciones y seminarios. Los testimonios de estudiantes indicaron una alta efectividad de la disciplina propuesta a través de sus temas rectores, de enseñanza y actividades personalizadas. Con eso los estudiantes de primer año informaron una transición más suave de la escuela secundaria a la educación superior.

Palabras clave: Educación superior; Recién llegado; Adaptación universitaria; Recepción; Orientación académica; Educación remota de emergencia.

\section{Introdução}

A pandemia de coronavírus, declarada em 11 de março de 2020 pela Organização Mundial da Saúde (OMS-WHO), levou a Universidade Federal de Minas Gerais (UFMG) a suspender as aulas presenciais do $1^{\circ}$. semestre de 2020, a partir de 18 de março de 2020. Por meio desta ação buscou-se seguir orientações do Ministério da Saúde e da Prefeitura de Belo Horizonte para evitar atividades que gerassem aglomerações e mitigar o contágio (Who, 2020; Ufmg, 2020a). Dessa forma, as aulas iniciadas em 2 de março de 2020 contaram, apenas, com 15 dias letivos presenciais naquele ano, e a sua retomada somente cinco meses depois, determinada pela Resolução 02/2020 por meio do formato de Ensino Remoto Emergencial (ERE) (Ufmg, 2020a).

Apesar de já existirem orientações de como elaborar um curso - e seus materiais - para ensino à distância, inclusive com proposta de modelos de sua gestão organizacional (Perry \& Rumble, 1987), a pandemia impôs grande desafio e necessidade de adaptações ao ensino. Devido à urgência, não houve tempo hábil de adequar o ensino presencial ao modo de educação à distância. Dessa forma, um novo formato de ensino virtual e remoto (sob várias nomenclaturas diferentes) é que foi planejado. Para isso, foi necessário um intervalo de tempo para que as instituições, escolas e universidades, preparassem novas diretrizes temporárias para o ERE (Rabello, 2020).

Um grande arsenal eletrônico, com diversos recursos interativos, foi criado, mundialmente, para a realização de reuniões remotas como teleconsultas, auxílio ou atendimento psicológico a pessoas vulneráveis, diversão, lazer e ensino.

No que se refere a educação, a situação lançou uma luz sobre áreas que precisam ser melhoradas para o futuro (Kawaguchi-Suzuki, 2020).

$\mathrm{Na}$ China, com o lema 'parem as aulas, mas não parem de aprender', o governo pôs 240 milhões de crianças e jovens a aprender pela internet, disponibilizando mais de 24 mil cursos gratuitos de ensino técnico e superior em plataformas virtuais. A diferença é que o governo chinês já investia fortemente em educação para um novo jeito de ensinar e de aprender, há muitos anos (Oliveira, 2020; Rabello, 2020).

Cicha e colaboradores (2020) discorrem sobre as diferentes regulamentações do ensino remoto em seu próprio país, a Polônia e em outros países, como a Alemanha, Vietnã, Holanda, Estados Unidos. Verificaram que problemas de infraestrutura, falta de experiência dos professores e alunos (analfabetismo digital) com o formato virtual de ensino, somada à falta de clareza das informações, complexidade do trabalho, bem como estudos no ambiente doméstico impactaram a qualidade na educação.

Crawford e colaboradores (2020) relatam as iniciativas institucionais tomadas no período da pandemia, em universidades de 20 países do mundo. Notaram que não houve uma rápida resposta para a recurricularização remota, mas pôde- 
se tirar proveitos pedagógico de aprendizado com outras universidades para fortalecer uma resposta coletiva a COVID-19, agora e para o futuro, além de mudar o olhar com foco para um currículo integrado (Castaman \& Rodrigues, 2020).

Quanto aos Cursos de Farmácia, experiências relatadas nos Estados Unidos, Japão, Nigéria e Reino Unido apontam que os educadores não só enfrentaram desafios, mas também, oportunidades de conversão do modo de ensino em sala de aula, em laboratórios, e vivências em criatividade para o ensino e comunicação mais intensa com os estudantes (Kawaguchi-Suzuki, 2020).

"A pandemia apenas expôs a nervura do real. Ela permitiu olhar um pouco mais demorado sobre a práxis, o que está sendo feito e como está sendo feito" (Castaman \& Rodrigues, 2020).

\subsection{O ensino remoto na UFMG}

No Brasil, não foi diferente. Situada no estado de Minas Gerais, A UFMG, por meio da administração central e da PróReitoria de Graduação - Prograd, realizou inúmeras reuniões on-line para fins de orientação, informação e treinamento dos servidores. Vale destacar o Programa Integração Docente: Ações Formativas para as Práticas Pedagógicas, um espaço virtual, oficialmente lançado em junho de 2020, para o fortalecimento, discussão e compartilhamento sobre as práticas de ensino, para além do ERE (Ufmg, 2020b).

Recomendações e ações foram realizadas a fim de garantir a acessibilidade a alunos deficientes no ensino não presencial, bem como a preservação de ações extensionistas em prol da saúde mental, por meio do Núcleo de Acessibilidade de Inclusão NAI, e da Pró-Reitoria de Extensão - PROEX, respectivamente (Ufmg, 2020c).

O distanciamento físico ocasionado pela pandemia impôs à comunidade a necessidade de auxilio profissional no campo da saúde física, mental, e de orientação educacional. Em continuidade às ações, pré-existentes ou não, a UFMG disponibilizou uma página eletrônica para o acolhimento à comunidade em todos os seus níveis funcionais, no Brasil e no exterior, como terceirizados, técnicos administrativos em educação, docentes, discentes, estudantes das moradias universitárias (Belo Horizonte e Montes Claros), pessoas com deficiência e trabalhadores dos hospitais vinculados.

A Rede de Saúde Mental, em seu canal aberto à comunidade, os atendimentos on-line, em grupo ou individual, tiveram lugar garantido por meio de projeto de extensão do Departamento de Psicologia da UFMG por meio do Serviço de Psicologia Aplicada (SPA). Além disso, com o projeto Acolhimento à Distância, ofertava-se acolhimento e escuta empática à comunidade universitária. Para os servidores da UFMG, foi estabelecido atendimento individualizado realizado pelo Departamento de Assistência à Saúde do Trabalhador (DAST) e Pró-Reitoria de Recursos Humanos (PRORH) via ferramentas de tecnologia da informação e teleconsulta (Ufmg, 2020c).

A UFMG anunciou o retorno letivo de 2020-1, no modo ERE, para o dia 3 de agosto de 2020, e recomendou o uso de Plataformas virtuais tais como, Moodle, Microsoft Teams, além da sua própria, a Minha UFMG, para o acompanhamento das aulas remotas em modo, preferencialmente, assíncrono (Ufmg, 2020a; Ufmg, 2020b).

Na UFMG, houve grande empenho dos professores, monitores graduandos e pós-graduandos em repensar e planejar as aulas para o novo formato de aulas gravadas que foram oferecidas de modo assíncrono. Opcionalmente, e a critério docente, aulas síncronas poderiam acontecer, de modo a estreitar relações com os estudantes. As avaliações dos alunos tiveram que ser alteradas para o formato eletrônico e remoto em plataformas adequadas, que tivessem capacidade de atender milhares de pessoas conectadas simultaneamente, e sob a necessária estabilidade de sinal digital.

\subsection{O ensino remoto no Curso de Farmácia}

Vencida a resistência de alguns professores, todas as disciplinas obrigatórias e optativas teóricas, teórico-práticas, ou práticas foram ofertadas no modo virtual, à exceção apenas para três optativas. Obviamente, houve desafios e estresses para todas 
as partes envolvidas, pois a maioria dos professores não possuía habilidades técnicas e/ou pedagógicas para a criação de materiais de qualidade para o ensino remoto, assim como aconteceu em outros lugares do mundo (Wray et al., 2008; McNair-Crews, 2015; Castaman \& Rodrigues, 2020).

A Faculdade de Farmácia que conta com o Serviço de Escuta Acadêmica - Escuta Fafar - desde 2017, continuou a realizar, durante a pandemia, a escuta atenta dos estudantes, suas trajetórias acadêmicas e necessidades, além do acompanhamento de estudantes com maior vulnerabilidade (principalmente, os do primeiro ano), deficiência, baixo rendimento escolar ou sob risco de evasão (Vasconcelos et al., 2017, Vianna-Soares et al., 2018; Ruas et al., 2019). As escutas dos estudantes foram realizadas pela assessora pedagógica e/ou coordenadora/subcoordenadora do Colegiado de Curso.

Adicionalmente, muitas atividades educacionais realizadas anteriormente, em modo presencial, tiveram sua conversão para o modo virtual, tais como, a recepção aos ingressantes (de primeiro ano, transferência, obtenção de novo título ou reopção), promoção de rodas de conversas temáticas para tratar de demandas coletivas, palestras, aulas dialógicas sobre as Normas Gerais de Graduação - NGG da UFMG - antes permeadas na disciplina Farmácia e Sociedade, e outras (Ufmg, 2018).

Após a suspensão das aulas, devido à pandemia estabelecida, as rodas de conversa passaram a ser virtuais, com frequência semanal. $\mathrm{O}$ formato virtual assim permaneceu até o encerramento do $1^{\circ}$. semestre de 2020 no modo ERE, quando houve a necessidade de reunião destas atividades de maneira sistemática, o que resultou na criação da disciplina "Orientação à Vida Acadêmica no Curso de Farmácia (OVA-CF)". A disciplina (15 h equivalente a 1 crédito) foi aplicada com oferta experimental e optativa em 2020-2 para 32 estudantes, e em 2021-1, após aprovação pela Câmara Departamental, para 40 estudantes do diurno e 17 do noturno. Com isso, os objetivos eram proporcionar aos ingressantes informações acadêmicas e atividades personalizadas que lhes trouxessem adaptação e vinculação universitária (Teixeira et al., 2008; Matta et al., 2017), além de percepções e construções próprias.

Nota-se que a orientação aos estudantes é essencial, uma vez que os calouros ou ingressantes na UFMG não tiveram contato com outros estudantes veteranos do curso e possuem muitas dúvidas em relação a vida acadêmica universitária ao participar do ERE proposto.

A implantação desta disciplina vem ao encontro da preocupação da UFMG com o grau de pertencimento dos estudantes, a sua vinculação e permanência até a conclusão do curso.

\section{Metodologia}

A proposta da disciplina foi apresentada mediante um projeto de ensino, elaborado contendo os seguintes itens: situação, justificativa, objetivos, resultados, abrangência, ações, atividades ou tarefas e referências. A finalidade da criação da disciplina foi promover atividades abrangentes e acolhedoras aos estudantes do Curso de Farmácia da UFMG e fornecer fontes para estudo experimental, observacional e documental no modo relato de experiência para verificação da eficiência da disciplina (Pope \& Mays, 2009; Minayo, 2012; Ludke \& André, 2013) O consentimento livre e esclarecido, por parte dos estudantes foi obtido no início da disciplina para fins de utilização anônima e adaptada de depoimentos, relatos ou atividades realizadas.

As plataformas virtuais utilizadas para apoio à aprendizagem - Moodle (Modular Object-Oriented Dynamic Learning Environment) e Microsoft 365® Teams - foram aquelas sugeridas pela Pró-reitoria de Graduação (Prograd-UFMG). Outras plataformas disponíveis na internet também podiam ser utilizadas durante o ERE, caso necessário.

A disciplina criada apresenta em sua ementa diversas atividades com o foco de explanar, aos discentes, a estrutura curricular do Curso de Farmácia, as normas acadêmicas vigentes na UFMG e outras atividades vinculativas ao curso e a universidade. Temas relevantes para aumentar o bem-estar e melhorar a qualidade de vida de todos, tais como técnicas de relaxamento e concentração, gestão do tempo e da saúde mental foram trabalhados.

A sua estrutura foi organizada em cinco módulos, como destacado a seguir. 
- Recepção aos Calouros, com apresentação das hierarquias acadêmicas e serviços de apoio na FAFAR; Conhecimento dos acadêmicos ingressantes (de primeiro ano, transferência, obtenção de novo título ou reopção), deficientes e procedentes de outras regiões geográficas no Curso de Farmácia da UFMG.

- Estudo das Normas Gerais de Graduação (NGG) da UFMG e/ou do respectivo Regulamento do Curso de Farmácia; Noções de normas e ética acadêmicas;

- Organização do tempo durante a vida universitária; A inserção universitária no contexto familiar e social, no presente e suas projeções;

- Expectativas e formas de vinculação à vida universitária por meio de representações estudantis e do Serviço de Escuta Acadêmica - Escuta FAFAR na valorização e acompanhamento do estudante;

- Planejamento de Estudos para matrículas futuras de acordo com a matriz curricular e percepções da efetividade da disciplina.

As aulas propostas no conteúdo programático do plano de ensino da disciplinaforam ministradas de modo síncrono, de forma a permitir mais interações, e ainda assim, foram gravadas para permitir o acesso posterior.

As atividades durante as aulas, geralmente, contavam com três fases, descritas a seguir:

- Inicial: etapa de abertura da aula, que começava com uma frase meditativa, normalmente referenciada em livros de desenvolvimento pessoal, como por exemplo, O Palhaço e o Psicanalista (Dunker \& Thebas, 2019), A Coragem de Ser Imperfeito (Brown, 2016). As mediadoras questionavam os participantes sobre o seu bem-estar e os escutava. As manifestações e sentimentos que os estudantes traziam eram acolhidas para aquele momento. Seguia-se a meditação guiada em voz alta, com solicitação de posicionamento corporal confortável, sem cruzar mãos e pés, em ambiente silencioso. Ao término, novas questões, referentes ao bem-estar e sentido para cada um, eram levantadas e comentadas;

- Intermediária: etapa destinada às atividades de ensino e personalizadas para informação, debates ou adaptação e vinculação universitária dos estudantes;

- Final: etapa de fechamento das atividades, em que a mediação verificava como os participantes saíam do encontro, qual o sentimento que carregavam para a preparação ou desenvolvimento de atividades diversas durante a semana. Outras informações pertinentes para a realização de atividades personalizadas ou acadêmicas eram passadas aos participantes. 


\subsection{Atividades personalizadas desenvolvidas na disciplina}

\subsubsection{Atividade Mapeando o Eu}

Nesta atividade a mediação solicitava aos estudantes fazer um desenho de si mesmos, a partir de um esboço de um corpo humano e escrever adjetivos que os caracterizem.

\subsubsection{Atividade Eu Presente e Eu Futuro}

Os estudantes realizavam uma análise temporal comparativa e prospectiva por meio de esquemas, imagens e/ou palavras-chave que os representassem, em seu atual contexto e com setas indicativas de ações para alcance dos fins em etapa futura de suas vidas. Diferentes áreas da vida deviam ser contempladas, como a pessoal, profissional, familiar, acadêmica e amorosa.

\subsubsection{Atividade Roda da Vida}

Num desenho circular na forma de radar, equivalente ao panorama de vida, como exemplificado na Figura 1, os estudantes preenchiam (cor e número) os quadrantes, no sentido horário, referentes aos aspectos Pessoais, Profissionais, Relacionamentos e Qualidade de Vida. Dessa forma, podiam relacionar, quantificar, colorir, avaliar e refletir sobre o somatório, para suas vivências.

Figura 1. Roda da Vida, tipo radar, com quatro quadrantes, segmentados em raias quantificadas de 1 a 10, disponibilizada aos alunos para avaliação da satisfação pessoal em diversos setores da vida.

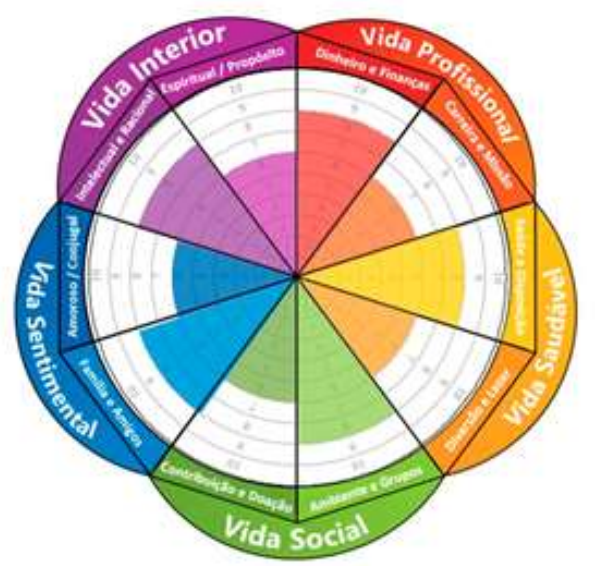

Fonte: https://static-media.hotmart.com/9MmYwaqEHT7qk-9W6Wup-aT5Qyo=/600x600/smart/filters:format(jpg):ba ckground_color(wh ite)/hotmart/product_pictures/caa0d8d1-2b90-4478-97a8-2b981ca35603/Capturar.PNG.

\subsubsection{Atividade com mandala}

Nesta atividade, os alunos eram convidados a colorir, a seu critério pessoal, desenhos esquemáticos de diferentes modelos de mandalas (Green, 2005), contendo em seu interior formas geométricas ou da natureza variadas. A busca por outros modelos de mandalas em sites específicos foi possibilitada. 


\subsection{Atividades de ensino desenvolvidas na disciplina}

Nas atividades acadêmicas, a mediação apresentou pontos relevantes sobre o Curso de Graduação em Farmácia, além de normas vigentes, a universidade e suas instâncias administrativas, as atividades culturais, artísticas, esportivas, estudantis e descreveu linhas sobre o vasto campo e atuação profissional farmacêutico. Palestrantes do Departamento de Psicologia e de Produtos Farmacêuticos da UFMG, normalmente, são convidados a discorrer sobre as dimensões do homem no refazer da vida, e as áreas de atuação profissional, respectivamente.

Como forma de fixação e aprendizado, foram aplicados três quizzes avaliativos a respeito das normas acadêmicas e um referente à atividade personalizada (fabricação de mandala), com aplicação de conceitos. As questões fechadas foram elaboradas sob a forma de diferentes modalidades.

Além disso, dois seminários, em grupo, encerram as atividades acadêmico-pedagógicas propostas. As finalidades destas atividades são o preparo para a elaboração de planos de estudos futuros para dois semestres subsequentes do curso e a criação de vídeo sobre a percepção da efetividade da disciplina.

\section{Resultados e Discussão}

Diante da regulamentação imposta pela pandemia por meio das diversas resoluções publicadas, os estudantes do Curso de Farmácia da UFMG puderam participar de atividades expositivas síncronas e remotas, ao mesmo tempo acolhedoras e informativas, e promotoras de experiências associadas ao ensino-pesquisa-extensão na disciplina OVA-CF da FAFAR-UFMG (Cunha, 2011).

$\mathrm{Na}$ etapa inicial das aulas, a proposição de frases reflexivas induzia a reflexões pertinentes à vivência acadêmica, familiar e/ou social dos participantes. $\mathrm{O}$ acolhimento aos estudantes se iniciava neste momento, um espaço para exposição de dúvidas, questionamentos, sentimentos, angústias ou desabafos relacionados à vida universitária. Além da escuta ativa, esta ação gerava sentimentos de empatia e acolhimento nos estudantes, a exemplo de acolhimentos e rodas de conversa para uma construção libertadora, desenvolvidos com adolescentes do sertão pernambucano, por Sampaio e colaboradores (2014).

Na prática de meditação guiada os estudantes se familiarizavam com técnicas de respiração e foco. Segundo Rempel (2012) a prática meditativa pode ser definida de diversas formas, mas pode ser caracterizada, basicamente, como práticas de autorregulação focadas no treinamento da atenção e consciência, a fim de promover maior controle voluntário pelo indivíduo, permitindo o desenvolvimento de capacidades como calma, clareza e concentração, focando sua atenção em um propósito, no momento presente e sem julgamentos.

Novamente questionados após a meditação, os alunos manifestavam satisfação, alívio da ansiedade, de dor de cabeça e de outros sintomas físicos relacionados ao estado de sua tensão.

Esta atividade pode ajudar na transição de um estado mental de intensa atividade para uma postura interna de não ação e de controle atencional intencional. Ao contrário do que muitos pensam sobre a ausência de pensamentos na meditação, cada pensamento, sensação eram acolhidos e observados sem julgamento, da forma que se apresentavam. Com esta atitude de abertura diante dos pensamentos e sentimentos o estudante pode modificar o modo como eles são experienciados.

A exposição contínua à auto-observação de pensamentos e emoções sem desviar ou evitá-los irá ajudar na diminuição das emoções negativas e na extinção de respostas de medo ou comportamentos de evitação. O estado de atenção plena é uma "habilidade que deve ser aprendida, sendo assim, a competência deve ser desenvolvida gradualmente, ao longo do tempo. Para tanto, é necessário que a prática seja disciplinada e regular" (Melo et al., 2014, p. 230; Goleman, 1999, p.14).

A prática regular da meditação está relacionada a vários indicadores da saúde física e psicológica, como, por exemplo, maior equilíbrio do sistema nervoso autônomo (simpático e parassimpático), níveis mais elevados de afeto positivo, satisfação com a vida, vitalidade e menores níveis de afetos negativos e de outros sintomas psicopatológicos (Martí et al., 2016, p. 21). 
Com a prática da meditação não se objetiva mudar o conteúdo dos pensamentos, a ênfase, na verdade, está em mudar a consciência e a relação com os pensamentos, permitindo que o estresse emocional seja vivido de modo menos desagradável. Desta forma, aprende-se a desenvolver suas próprias respostas adaptativas e reduzir condutas mal adaptativas ou impulsivas diante da situação vivida. Ao enfrentar com serenidade momentos negativos e aprender a desfrutar mais dos positivos, promovese o resgate na crença na vida e o florescimento da pessoa. Há uma postura de aceitação mais plena e consciente com relação a cada momento vivido.

Nota-se que esta prática colabora para uma maior aceitação de sensações, autopercepção, autoconsciência dos processos internos. Propulsiona, ainda, tomadas de decisão mais intencionais, um relaxamento mental e físico, e diminui a ansiedade.

Práticas meditativas têm sido usadas no contexto escolar porque ajudam os estudantes a convergir a atenção em classe, regular melhor suas emoções, ter mais calma e autoestima, gerenciar as distrações, sentar-se com postura adequada, respirar melhor, além de adquirir maior habilidade nas inter-relações sociais (Cosenza, 2019, p. 1). Por isso, a prática meditativa é uma estratégia a incorporar no cotidiano, de modo regular.

O estudo realizado por Napoli e colaboradores (2005) indica que a incorporação de práticas meditativas no currículo está associada à melhoria do desempenho acadêmico. Diante disso, o papel das escolas ultrapassa a tarefa de ensinar disciplinas e conteúdos. É necessário inovar e propor estratégias que possibilitem aos estudantes viver e conviver no mundo contemporâneo. Currículos, que antes, em sua maioria, sufocavam a criatividade, a curiosidade e o entusiasmo através da passividade e do aprendizado superficial, passam então a oportunizar a flexibilidade, a inventividade e um aprendizado mais significativo (Rempel, 2012).

Após a prática meditativa, seguiam-se as outras atividades, acadêmicas ou personalizadas.

$\mathrm{Na}$ atividade Mapeando o $\mathrm{Eu}$, os estudantes visualizavam sua história de vida e se apercebiam de seu lugar na universidade e sociedade. Aprofundavam o conhecimento sobre si mesmos, canalizado por meio de suas qualidades e habilidades, o que levava a percepção e reflexão sobre a sua autoimagem, no presente.

$\mathrm{Na}$ atividade Eu Presente, Eu Futuro, os estudantes prospectavam planos e projetos a longo prazo, o que instigava a motivação em relação a seus anseios, sonhos e perspectivas. As formas e meios necessários para a concretização das conquistas desejadas também deviam estar mencionadas. Diversas demonstrações desta atividade foram realizadas pelos ingressantes para fins de reflexão de seus objetivos e metas, do presente até a prospecção de futuro, num intervalo de tempo de sete anos, como exemplificado na Figura 2. 
Figura 2. Demonstração infográfica desenvolvida por estudante na atividade personalizada 'Eu Presente, Eu Futuro` Disciplina Orientação à Vida Acadêmica no Curso de Farmácia (OVA-CF) - FAFAR-UFMG, para a sua prospecção de vida pessoal e profissional, em intervalo de tempo de sete anos.

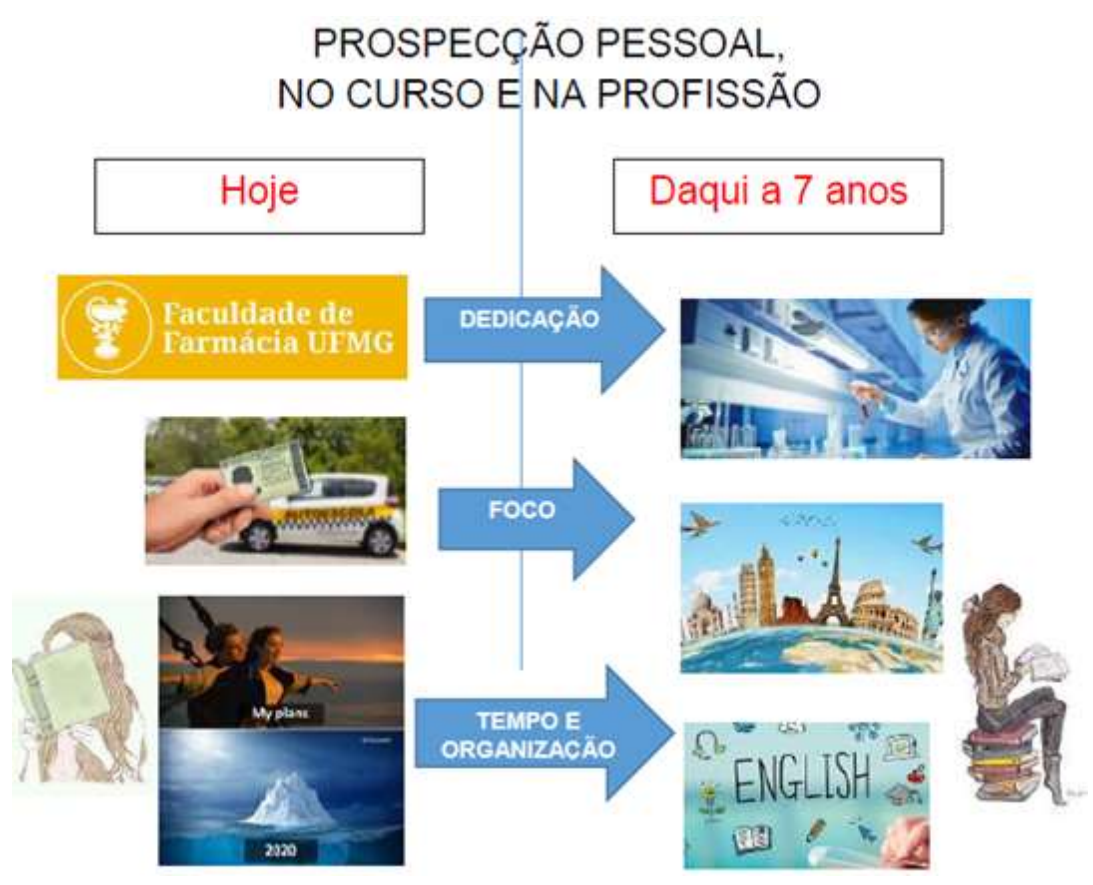

Fonte: Autores (2021).

Na atividade Roda da Vida, os estudantes puderam ter a oportunidade de refletir sobre seu panorama de vida, e constatar alguma condição desarmoniosa. Considerando a gestão do tempo, em diferentes áreas da vida, como a pessoal, profissional, familiar, acadêmica e afetiva, eles detectavam áreas deficientes, a exemplo daquelas pouco conceituadas na escala das raias quantificáveis e se propunham a buscar equilíbrios, onde necessário.

O desenvolvimento desta atividade com mandalas traduz elementos psicoemocionais do indivíduo, além de favorecer o relaxamento para foco na expressão de sentimentos e emoções, significativos a cada um (Mendonça \& Brito, 2017).

O ritmo de vida atual conduz o homem a uma desconexão de si mesmo e a uma separação do corpo, do mental e do espírito. Trabalhar com mandalas favorece essa reconexão de maneira que o indivíduo se sinta completo e íntegro - ligado à natureza, à vida, ao mundo que o envolve. A contemplação de uma mandala pode inspirar a serenidade e ajudar a reencontrar um sentido, ordem na vida e alcançar a paz interior (Lisboa da Cunha, 1998, p. 140-141).

Os benefícios da atividade de fabricar, ou colorir mandalas, também já são reconhecidos para o tratamento de patologias como depressão, déficit de atenção e estresse (Menezes, Fiorentin, Bizarro, 2012). Além disso, Dibo (2009) em suas pesquisas com mandalas em contexto de sala de aula também ressalta os seus benefícios sobre a atenção direcionada.

Como ferramenta de centramento e aporte terapêutico de caráter calmante a atividade com Mandalas estimulou os estudantes a contemplar o desenho e atribuir cores, vislumbrar propriedades de suas personalidades, refletir sobre gostos e afinidades, individualidade e autonomia. Os participantes relataram alcance de concentração, compartilhamento/envolvimento familiar e dissociação de problemas, atingindo momento de tranquilidade raro, dentre as atribulações estudantis.

Ao final da disciplina, muitos relatos colhidos vieram acompanhados de nítidas percepções positivas acerca do estado emocional dos estudantes, que evidenciaram melhores conciliação de tarefas e afazeres, gestão do tempo e controle de suas emoções.

A inclusão desta atividade no cronograma da disciplina OVA-CF foi uma decisão acertada, já que a adesão estudantil foi significativa e evidenciada por depoimentos, exemplificado na Figura 3. 
Figura 3 Mandala e relato elaborados por estudante na atividade com Mandalas - Disciplina Orientação à Vida Acadêmica no Curso de Farmácia (OVA-CF) - FAFAR-UFMG.

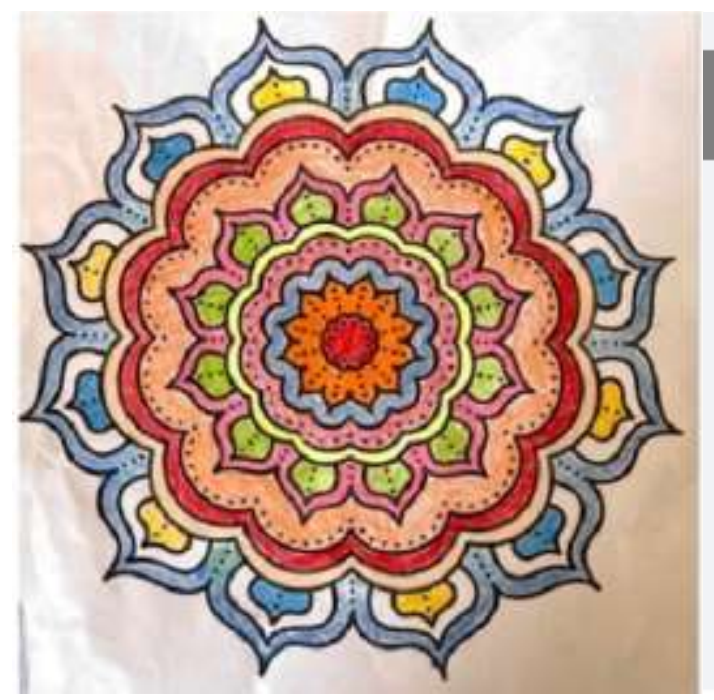

Comentários de estudante após a realização da atividade Mandala a Colorir:

Após a realização desta atividade, me senti bastante relaxada e calma, porém bastante focada. Dessa forma, acredito que isso ocorreu por eu ter parado em um momento da minha rotina para me dedicar unicamente à uma prática, que é bastante utilizada para provocar esse tipo de sensação. Portanto, acredito que pretendo aderir essa dinâmica ao meu dia a dia, para até mesmo causar uma atmosfera de relaxamento e melhorar meu rendimento nas atividades cotidianas.

INTENÇÃO: foco e relaxamento; SENTIMENTO: calma, bem-estar e concentração; PENSAMENTOS: tranquilos e "organizados"; RETORNO: Concentração, gratidão pela vida e oportunidades.

Fonte: Autores (2021).

No momento intermediário das aulas, além das atividades interativas acima mencionadas, foram introduzidos aspectos acadêmicos com o foco de levar informações importantes. Os temas propostos em cronograma sobre as NGG foram bem discutidos por meio da simulação de casos, e espaços para perguntas e exemplificações. Isso facilitou o entendimento e aumentou muito o interesse em conhecer as normas acadêmicas.

O conhecimento sobre as NGG trouxe conscientização e tranquilidade sobre a trajetória dos estudantes no curso, além de percepção da valorização de seu lugar em uma universidade federal, em um contexto de ocupação de vaga em curso da área de saúde. A reflexão sobre estes valores implica na responsabilidade atitudinal frente a tal investimento público, reforçando a contrapartida de cada estudante para a sua devolutiva à sociedade.

As atividades, tanto personalizadas, quanto acadêmicas realizadas na disciplina OVA-CF proporcionaram interações iniciais para despertar o vínculo estudantil com a universidade, bem como conhecimentos de trâmites acadêmicos próprios do curso e da instituição para o ingressante continuar em sua trajetória de forma orientada e satisfatória. Desse modo, o acolhimento ao ingressante de Farmácia, a sua introdução às normas acadêmicas e a adaptação universitária foram repensados de modo criativo e motivacional, virtual e sincronamente, durante a pandemia de coronavírus.

Bissonnette e colaboradores (2020) em seu trabalho, intitulado 'Para revolucionar a formação docente: propostas de intervenções baseadas em evidências`, mostra que a exemplo da medicina baseada em evidências, melhorias na educação são possíveis, desde que fundamentadas em provas (evidências, resultados de pesquisas) de alta eficácia (validadas de forma científica).

Conforme exposto, a disciplina contribuiu não só para a formação do estudante e seu aprendizado, por meio de gestão testada em sala de aula e validada por entrevistas dos estudantes, mas também para a formação de professores, mediadores e monitores, pois se apoiou em orientações acadêmicas, realismo crítico e uso de valores (Bissonnette et al., 2020; Cunha, 2011). Ademais, os alunos vislumbraram a importância da implementação da disciplina OVA-CF, de forma efetiva e obrigatória, pois lhes proporcionou valores, benefícios à saúde, mudança de hábitos organizacionais e conhecimento fundamental para a sua trajetória universitária na UFMG, como apresentado na Figura 4. 
Figura 4. Valores e benefícios relatados pelos participantes da disciplina Orientação à Vida Acadêmica no Curso de Farmácia (OVA-CF), confirmando a importância de sua implementação no curso.

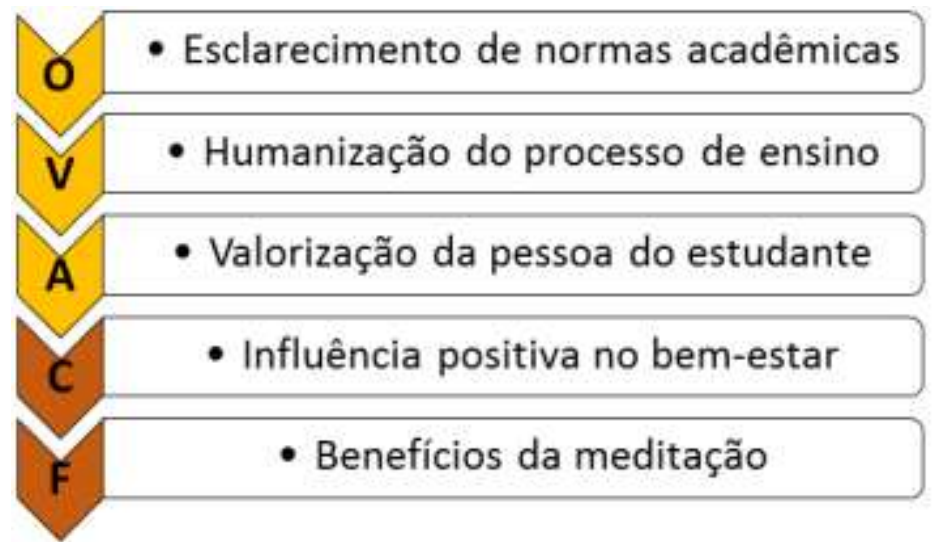

Fonte: Autores (2021).

Quanto a efetividade da disciplina, alguns comentários favoráveis, foram:

"A disciplina é importante para mostrar o caminho, pois se fosse para fazer sozinho, não o faria";

"Queria entender até onde eu podia chegar, de acordo com as regras da universidade, o que ajuda a pessoa leiga a se conduzir no percurso";

"A disciplina é importante para aprender a se planejar, a exemplo da atividade Roda da Vida";

"As atividades (principalmente, a palestra da psicóloga) fizeram com que olhássemos para nós mesmos, para além do estudante, da faculdade";

"Eu vi essa matéria como uma espécie de conforto, mesmo porque foi meu primeiro semestre, eu não tinha muita noção de nada, eu nunca entrei no prédio da Faculdade de Farmácia. Então, esta disciplina me fez aproximar tanto dos professores quanto do próprio Curso de Farmácia. Foi bom, porque calouro sempre chega um pouco perdido na faculdade, então foi muito bom para a gente ter um norte, de como vai funcionar daqui para frente".

Segundo Berbel (2011), o estudante tão mais se engaja a novos conhecimentos e aprendizagens quando vislumbra possibilidades que lhe conferem liberdade e autonomia para tomadas de decisão, em diferentes momentos de sua formação profissional. Mudanças ativas e satisfatórias são o resultado, combinado com a motivação, de hábitos que levam à ação e de conhecimentos que guiam as ações para transformação de uma prática ou realidade.

\section{Considerações Finais}

Com a criação da disciplina OVA-CF, constata-se que os estudantes puderam vivenciar cuidados com a sua saúde física e mental, bem como uma melhoria na gestão da vida acadêmico-profissional ao serem introduzidos a práticas meditativas, reflexivas, e informativas, aplicáveis à vida universitária num longo prazo.

Dessa forma, o ingressante do Curso de Farmácia da UFMG foi acolhido e apoiado em suas necessidades pedagógicoeducacionais iniciais, conheceu mais o curso escolhido; aprendeu a reservar tempo para gerir os estudos e foi orientado para a sua permanência universitária, de modo prazeroso. Como trabalhos futuros referentes à disciplina OVA-CF, vislumbra-se a sua 
incorporação como componente curricular nos cursos de graduação, ampliando a visão de trazer diferentes significados para o estudante, orientação, além de reforço para vínculos motivacionais durante a sua trajetória acadêmica.

\section{Agradecimentos}

Ao Colegiado de Coordenação Didática do Curso de Farmácia e à Diretoria da Faculdade de Farmácia da UFMG pelo apoio logístico-administrativo, desde a criação do projeto ESCUTA FAFAR, e à Prograd-UFMG pelas bolsas concedidas aos graduandos TSS, RCM e GMMM.

\section{Referências}

Berbel, N. A. N. (2011). As metodologias ativas e a promoção da autonomia de estudantes. 2011. http://proiac.sites.uff.br/wpcontent/uploads/sites/433/2018/08/berbel_2011.pdf.

Bissonnette, S., Gauthier, C., \& Bocquillon, M. (2020). Para revolucionar a formação docente: propostas de intervenções baseadas em evidências. Educação em Perspectiva/Education in Perspective. 11, 1-9, e020013.

Brown, B. (2016). A Coragem de Ser Imperfeito. Sextante. 208 p.

Castaman, A. S., \& Rodrigues R. A. (2020). Educação a distância na crise Covid-19: um relato de experiência. Research, Society and Development, 9(6), e180963699. http://dx.doi.org/10.33448/rsd-v9i6.3699.

Cicha, K., Rizun, M., Rutecka, P., \& Strzelecki, A. (2021). Covid-19 and higher education: first-year students' expectations toward distance learning. Sustainability, 13(4), 1889. https://doi.org/10.3390/su13041889.

Cosenza, R. (2019). Prática de mindfulness no ambiente escolar pode trazer benefícios a alunos e professores. Revista Neuroeducação, 246, 1-5. https://www.revistaeducacao.com.br/pratica-de-mindfulness-noambiente-escolar-pode-trazer-beneficios-a-alunos-e-professores.

Crawford, J., Butler-Henderson, K., Rudolph, J., Glowatz, M., Burton, R., Malkawi, B., Magni, P. A., \& Lam, S. (2020). View of Covid-19: 20 countries' higher education intra-period digital pedagogy responses. Journal of Applied Learning \& Teaching, 3, 1-20. https://doi.org/10.37074/jalt.2020.3.1.7.

Cunha, M. I. (2011). Indissociabilidade entre ensino e pesquisa: a qualidade da graduação em tempos de democratização. Perspectiva, 29(2), 443-462., https://periodicos.ufsc.br/index.php/perspectiva/article/view/2175-795X.2011v29n2p443.

Dibo, M. (2009). Prabhã-mandala: os efeitos da aplicação do desenho da mandala no comportamento da atenção concentrada em adolescentes. Último Andar, 17, 9-20. https://revistas.pucsp.br/index.php/ultimoandar/article/view/13271/9786.

Dunker, C. \& Thebas, C. (2021). O Palhaço e o Psicanalista. Paidós. 256 p.

Goleman, D. (2018). A Arte da Meditação. Sextante. 112 p.

Green S. (2005). El Livro de los Mandalas del Mundo. Océano Âmbar.

Kawaguchi-Suzuki, M., Nagai, N., Akonoghrere, R. O, \& Desborough, J. Á. (2020). Covid-19 pandemic challenges and lessons learned by pharmacy educators around the globe. American Journal of Pharmaceutical Education, 84. https://www.ajpe.org/content/84/8/ajpe8197.

Lisboa da Cunha, M. H. Espaço Real e Espaço Imaginário. Uapê - Espaço Cultural da Barra, 1998. 140-141.

Ludke, M. \& André, M. E. D. A. (2013). Pesquisas em educação: uma abordagem qualitativa. (2a ed.), E.P.U., 128 p.

Martí, A. C. Campayo, J. G. \& Demarzo, M. (2016). Mindfulness e Ciência: da Tradição a Modernidade. Palas Athena. 236 p.

Matta, C. M. B., Lebrão, S. M. G., \& Heleno, M. G. V. (2017). Adaptação, rendimento, evasão e vivências acadêmicas no ensino superior: revisão da literatura. Psicologia Escolar e Educacional, 21(3), 583-591. https://www.scielo.br/pdf/pee/v21n3/2175-3539-pee-21-03-583.pdf.

McNair-Crews, G. (2015). Investigating instructor perceptions of on-line teaching versus traditional classroom instruction. Dissertação de doutorado. Walden University, AL, EUA, 151f. https://scholarworks.waldenu.edu/cgi/viewcontent.cgi?article=2830\&context=dissertations\&httpsredir=1\&referer=.

Melo, W. V. (Org.) (2014). Estratégias Psicoterápicas e a Terceira Onda em Terapia Cognitiva. Sinopsys, 32p.

Mendonça, B. I. O., \& Brito, M. A. Q. (2017). Mandalas como recurso terapêutico na prática da gestalt-terapia. Revista IGT na Rede, 14(27), 273-290. http://pepsic.bvsalud.org/pdf/igt/v14n27/v14n27a09.pdf.

Menezes, C. B., Fiorentin, B., \& Bizarro, L. (2012) Meditação na universidade: a motivação de alunos da UFRGS para aprender meditação. Revista Semestral da Associação Brasileira de Psicologia Escolar e Educacional, 16(2) 307-314.

Minayo, M. C. S. (2012). Análise qualitativa: teoria, passos e fidedignidade. Ciência \& Saúde Coletiva. 17 (3)1-6.

Napoli M., Krech P. R., \& Holley L. C. (2005). Mindfulness training for elementary school students: the attention academy. Journal of Applied School Psychology, 21(1) 99-125. https://www.tandfonline.com/doi/abs/10.1300/J370v21n01_05. 
Oliveira, D. Como a China pôs 240 milhões de crianças e jovens a aprender pela internet. (2020). https://desafiosdaeducacao.grupoa.com.br/china-educacaocoronavirus/.

Perry, W. \& Rumble, G. (1987). A short guide to distance education. Cambridge: Internacional Extension College. 4-38. 1987.

Pope, C., \& Mays, N. (2009). Métodos qualitativos na pesquisa em saúde. In: Pope, C.; Mays, N. Pesquisa Qualitativa na Atenção à Saúde. (3a ed.), Artmed, p. 11-21.

Rabello M. E. (2020). Lições do coronavírus: ensino remoto emergencial não é EAD. https://desafiosdaeducacao.grupoa.com.br/coronavirus-ensino-remoto/.

Rempel, K. D. (2012). Mindfulness for children and youth: a review of the literature with an argument for school-based. Canadian Journal of Counselling and Psychotherapy, 46(3), 201-220.

Ruas C. M., Macedo A. C. S. T., \& Vianna Soares C. D. (2019). Escuta Fafar: implantação de escuta acadêmica para os estudantes do Curso de Farmácia da UFMG como estratégia de redução de evasão no ensino superior. In: UFMG pesquisa egressos. Org.: Las Casas E.B.; Cunha D.; Queiroz, T. UFMG.

Sampaio, J. et al. (2014). Limites e potencialidades das rodas de conversa no cuidado em saúde: uma experiência com jovens no sertão pernambucano. Interface (Botucatu), 18(2), 1299-1311. https://www.scielo.br/j/icse/a/dGn6dRF4VHzHQJyXHNSZNND/?lang=pt.

Teixeira M. A. P., Dias A. C. G., Wottrich S. H., \& Oliveira, A. M. (2008). Adaptação à universidade em jovens calouros. Revista Semestral da Associação Brasileira de Psicologia Escolar e Educacional (Abrapee), 12(1),185-202. https://www.scielo.br/pdf/pee/v12n1/v12n1a13.pdf.

Ufmg, Universidade Federal de Minas Gerais. (2018). Resolução Complementar CEPE nº 01 de 20 de fevereiro de 2018. Aprova as Normas Gerais de Graduação da Universidade Federal de Minas Gerais (UFMG). Boletim Informativo da UFMG, 27. https://www.ufmg.br/prograd/arquivos/NormasGerais.pdf.

Ufmg, Universidade Federal de Minas Gerais. (2020a). Resolução $\mathrm{n}^{\circ}$ 02/2020 de 09 de julho de 2020. Regulamenta o ensino remoto emergencial da UFMG durante periodo de pandemia da doença COVID-19. Belo Horizonte, MG. https://ufmg.br/storage/7/2/7/c/727cdac040b 9f81d6c3a531b0e3cafe7_15944093123508_526377393.pdf.

Ufmg, Universidade Federal de Minas Gerais. (2020b). Programa Integração Docente. Ações formativas para a prática docente https://www.ufmg.br/integracaodocente/wp-content/uploads/2020/07/recomendacoes-acessibilidade-ver2807f1.pdf.

Ufmg, Universidade Federal de Minas Gerais. (2020c). Coronavírus e saúde mental. https://ufmg.br/coronavirus/coronavirus-e-saude-mental.

Vasconcelos P. A., Álvares-Silva, T. H., André, L. C., \& Vianna-Soares C. D. (2017). A reestruturação do atendimento ao aluno de graduação em Farmácia como estratégia de promoção da permanência no ensino superior. In: III Congresso de Inovação e Metodologias no Ensino Superior. 2017, 2017, Belo Horizonte. Anais do III Congresso de Inovação e Metodologias no Ensino Superior. UFMG, 1, 1-10.

Vianna-Soares C. D., Macedo, A. C. S. T., \& Ruas, C. M. (2018). A escuta de estudantes do curso de Farmácia - UFMG. In: Congresso Saúde Mental e Trabalho - Mal-estar no Trabalho, 2018, Belo Horizonte. Anais do Congresso Saúde Mental e Trabalho - Mal-Estar no Trabalho. 1, 1-1.

Who Director-General's opening remarks at the media briefing on Covid-19 - 11 March 2020. https://www.who.int/dg/speeches/detail/who-director-general-sopening-remarks-at-the-media-briefing-on-covid-19---11-march-2020.

Wray, M., Lowental, P. R., Bates, B., \& Stevens, E. (2008). Investigating perceptions of teaching online and face to face. Academic Exchange Quaterly. 243247. https://www.academia.edu/12954490/Investigating_perceptions_of_teaching_online_and_f2f. 